\title{
Using Alumni Entrepreneurs Feedback to shape University Entrepreneurship Education
}

\section{Robert A. Phillips}

Manchester Enterprise Centre, Alliance Manchester Business School, University of Manchester, Manchester, U.K.

\begin{abstract}
It is accepted by most agencies that enterprise education is important for students and for the economy, however it is often difficult to measure the effectiveness of this education as effects can take many years to be shown. We have collected qualitative data from over 300 alumni entrepreneurs, reflecting on their time at the University of Manchester, which suggested that their experiences of enterprise education were mixed and that they would have benefitted from more practical courses rather than more academically interesting topics. For example they wanted training on how to register a company, understanding tax, employment law and basic book keeping, rather than how to generate ideas and theories of innovation and entrepreneurship. There is a clear need to shift some enterprise education to cater for those who have an idea now and need practical advice, or may have an idea in the future from their subject area and need to know how to proceed formally. On curricular courses are more likely to be academically and theory driven, especially with the need to provide appropriate assessment for students, whilst it is often the extracurricular activities which provide more practical details in how to start a business, which may not be open to all students, or may not be well advertised. Since many students don't start a business until later in life, with activity peaking in the 35-60 year old age group, they often do not take advantage of these opportunities while at university, should they be available. Our paper shows there needs to be a better mix of practical with academic courses to provide for alumni entrepreneurs' needs to allow them to start a business whether it be straight form university or later on in life.
\end{abstract}

Keywords: Alumni; Entrepreneurship and Enterprise Education; Employability; Impact; Training. 


\section{Introduction}

From its inception more than fifty years ago, the availability and breadth of entrepreneurship and enterprise education on offer has grown considerably, and although the outcomes are broadly positive, there are mixed views as to its effectiveness, with difficulties in measuring success particularly because of the time delay often between students graduating and starting a business later in life. However, all agree from policy makers, industry and employers to universities and students that entrepreneurship education is something students should be doing at university to some degree whether they end up starting their own business or working in a corporate environment (Volkman et al., 2009, Gibb, 2005). As a secondary effect, many studies have found that those alumni who have participated in enterprise education are more likely to be employed, earning a higher salary, and less likely to be underemployed that those who have not participated (EC 2015).

Initially entrepreneurship in university settings was about new venture creation, including those interested in university spin-outs but has come to include intrapreneurship as corporates often lose their entrepreneurial drive as they grow and more recently social entrepreneurship. Entrepreneurship has been defined by the QAA (2018) as the creation of social, cultural or economic value by creation of a venture. Intrapreneurship has been defined as the application of enterprising behaviours and skills within an existing organisation. Finally, Enterprise is a broader definition as the generation and application of ideas using a range of skills. Enterprise education focuses on equipping people with entrepreneurial skills and mind-set in a variety of contexts and is often linked to employability. Enterprise education generally includes any enterprising skills which could be used in a new workplace to create value (financial, social or cultural). Enterprise education is often linked to employability and many chartered bodies which oversee degree courses such as engineering, computer science and life sciences require commercial awareness to be included in all courses. Current data suggests approximately 5\% of UK students are self-employed six months after leaving university, with $0.6 \%$ having started their own business (HESA 2017).

Enterprise education is often offered now university wide in the UK - not just to business school students, many students are interested in commercialising their ideas from other subject areas (Smith et al., 2007, Jones et al., 2015). Enterprise education has a shown a wide range of effects. Some has no effect on entrepreneurial intentions or actual business creation. Some has shown an initial increase in self-efficacy followed by a slow decline; others show an increase in venture creation. Some training shows a negative effect, as people realise that the reality of entrepreneurship is harder than they thought and they realise it's not for them (perhaps not a bad thing to find out early). Meta-analysis has 
shown that overall there is a slightly positive effect of entrepreneurial education (Nabi et al., 2017). However, it seems an entrepreneurial ecosystem with inspiration and practical help is a good mix. There have been many other secondary benefits to enterprise education such as improved communication, presentation and team working skills (EC 2015).

On curricular courses include Masters courses with the aim of starting a business (Phillips and Styles, 2006), modules for entrepreneurship for business school students, optional or compulsory modules on entrepreneurship for those taking non-business degrees around the university, embedded entrepreneurship content such as case studies in modules within degree subjects, or for MBA students specific modules on entrepreneurship. Off curricular activities can include business plan and ideas competitions, hackathons, entrepreneurial speakers, skills workshops (e.g. starting a business, networking, creativity), on- or off-site boot camps (Phillips, 2017) and events where students can meet with entrepreneurs and these activities tend to be available university wide (Phillips, 2010, Phillips, 2018). On curricular courses often contain topics such as opportunity/problem recognition, market research, intellectual property, business planning, finance and sources of finance. Use of models such as PEST, Porters, SWOT and the Business Canvas are also common. Some courses also study traits of entrepreneurs and characteristics of entrepreneurial businesses. The need for assessment is also an issue - moving away from exams and more towards learning by doing such as suggested by Kolb Learning Cycle (1984) with assignments, posters, business plans, elevator pitches, personal reflective journals (Phillips, 2008), and problem based learning (Sanchez-Romaguera and Phillips, 2018). Universities are now using a variety of teaching methods and assessments in order to achieve enterprise education outcomes (Jones et al., 2015) where learning by doing is generally accepted to be more effective. The benefit of some off curricular activities such as business plan competitions is that there is further support from funding (often of the order of $£ 10,000$ ), publicity and in-kind support such as incubator space, mentoring and access to Intellectual Property lawyers.

Many scholars have studied the impact of enterprise education (for example, Fayolle and Gailly 2015, Oosterbeek et al., 2010, Matlay, 2008, Souitaris et al., 2007, Vesper and Gartner 1997) many students start a business later in life so longitudinal studies looking at venture creation may last many years - in fact data suggests venture creation is highest between the ages of 35-60. Self-efficacy and confidence are also commonly measured, but it is found the positive effect of a period of training can subside over time, and indeed, sometimes the entrepreneurial intent reduces as the student realises how hard starting a venture could be and the high chance of failure.

It is difficult for students to understand what might be needed to start an entrepreneurial venture before they have gone through the experience themselves and even staff with entrepreneurial experience within the university are likely to have gained this by spin-out 
company formation with help from the university and with the security of an academic position, so, students have a better idea once they have started a venture what they are likely to need so it was decided to contact alumni that had started a business to understand what else they would have preferred to see in training whilst at university.

We contacted alumni entrepreneurs to try to understand what type of enterprise education they felt worked well and what could universities do to better support students who might become self-employed upon leaving university.

\section{Methodology}

It was found that there were more approximately 10,000 alumni from the University of Manchester (approximately $2.5 \%$ of the database) who identified as being self-employed; a survey was advertised to these alumni who had set up businesses via LinkedIn, alumni newsletters and emails. It was self-selecting for those that respondent to the call to respond and 278 respondents replied to the survey and was administered via Surveymonkey.com. Respondents were from Engineering and Physical sciences (35\%), Humanities (20\%), Business (17\%), Biological/medical sciences (11\%), other $(16 \%)$. Their terminal qualification were Bachelor's degree (44\%), Taught masters (37\%), MBA (4\%) and Doctorate $(14 \%)$. Respondents were a variety of ages and had attended the university across several decades. Some had well established businesses; others were relatively new so we were able to collect a wide spectrum of view covering many years.

The key questions asked were did you feel university prepared you well for selfemployment and open comments on what they feel could have been done better. Data was collected from survey and qualitative comments analysed.

\section{Results and Discussion}

Firstly, alumni were asked in general whether they felt that the university had prepared them well for self-employment and the responses were mixed, but with $33 \%$ suggesting their experience was below average and only $15 \%$ saying very well it is clear that alumni feel much more could be done. 
Table 1: How well did the University prepare you for self-employment?

How well do you feel University prepare you for self-employment $\%$ of Responses

Very Well

Quite Well

Average

30.2

Poorly

10.4

Very Poorly

\section{Qualitative Comments}

In general, comments suggested that courses in entrepreneurship should be more practical dealing with the basics of registering a company and how the business functions. The answers were broadly split into practical skills (P), Gaining experience (E) and Networking (N). It should be noted that many older graduates had no specific training available to them, further than having done a general business degree or MBA course that they might have taken at university. 
Table 2: Comments made by Alumni Entrepreneurs

\section{Comments made by Alumni Entrepreneurs}

Training provided should be practical and relevant $(\mathrm{P})$

Universities should teach the basics of financial management $(\mathrm{P})$

Basic accounting should be taught $(\mathrm{P})$

Financial spreadsheets $(\mathrm{P})$

Budgeting should be taught $(\mathrm{P})$

How to register a company and the differences between the types of company structure $(\mathrm{P})$

Understanding taxation $(\mathrm{P})$

More opportunities for networking with entrepreneurs (N)

Arrange platforms to be able to speak to entrepreneurs in an informal setting (N)

Opportunities to work in a start-up /intern in a start-up not just corporates (E)

Work placements with self employed (E)

Possibility of doing an industry year out with self-employed not just big organisations (E)

Offer coaching and mentoring in specific cases for those with ideas $(\mathrm{P}, \mathrm{N})$

University could offer more funding for start-ups (P)

Signposts to funding and further advice to take an idea forward (N)

Offer personality testing $(\mathrm{P}, \mathrm{E})$

Doing practical projects (with entrepreneurs) (E)

Putting people in touch with each other who are interested $(\mathrm{N})$

Connecting people e.g. with business students or web/app developers $(\mathrm{N})$

Some said the university shouldn't be teaching entrepreneurship (-) 
Previous data (Phillips, 2018) suggests that only 33\% from a cross section of alumni were exposed to any entrepreneurship activities at university, so despite more activities being now available to younger graduates, it is possible these are not being advertised visibly enough.

\section{Conclusions and Recommendations}

From the results, it is clear that alumni entrepreneurs feel a shift towards increasing more activities that focus on practicalities is required. We suggest it could be offered extracurricular and would not necessarily need to be run by academics, but by the Chamber of Commerce, accountants or entrepreneurs themselves. This would be of benefit to those who are intending to start a business on graduating and will also help those students who will likely be self-employed (but not necessarily considered entrepreneurs) as a normal part of their job e.g. journalism, pharmacist, consultant etc. However, due to the latent nature of graduate start-ups, it is important to market these activities appropriately emphasising why commercialisation and practical entrepreneurial skills are important even for those in pure academia where a the academic may found a spin-out venture. Some student feedback from entrepreneurship courses (especially those that are compulsory) complains that students do not see the relevance of the course to their own work. We suggest there is more scope to focus purely on practicalities with extracurricular activities as no assessment is required, and a self-selecting audience of interested potential entrepreneurs.

Networks are important with joined up activities where things can move to the next stage, including more guidance for what they could do next - such as following a pipeline with overt links with accelerators and incubators and a commitment to help graduates after they have left. This is a common concern of students once they leave - providing a smooth transition from student entrepreneur to the commercial world. Alumni mentioned networking as an important aspect - to meet entrepreneurs in a more informal setting and also like minded students who could be potential co-founders or those with specialist skills such as coders and developers.

Many entrepreneurship courses and activities both curricular and off curricular offering topics of academic interest but clearly many entrepreneurs have ideas from elsewhere (so do not necessarily need creativity) and need to focus on practicalities. Undergraduate courses tend to be more general enterprise education as the relatively low numbers that start a business, so this enterprise education is used in an employability capacity and innovation studies / entrepreneurial studies are easier to assess in a more traditional manner. As far as existing entrepreneurship education is concerned, it should try to include practicalities of starting a business as well as the more intellectually stimulating activities such as creativity, innovation and studying entrepreneurial companies and models. 


\section{References}

EC (2015). Entrepreneurship Education: A road to success Luxembourg: Publications Office of the European Union, ISBN 978-92-79-44556-9 doi: 10.2769/408497.

Fayolle, A. and Gailly, B. (2015). The impact of entrepreneurship education on entrepreneurial attitudes and intention: Hysteresis and persistence, Journal of Small Business Management, 53(1), pp.75-93.

Gibb, A.A. (2005). Towards the entrepreneurial university entrepreneurship education as a lever for change, Policy Paper No. 003, National Council for Graduate Entrepreneurship (NCGE), Birmingham.

Higher Education Statistics Agency (2017). Report: Destinations of Leavers from Higher Education 2015-16 https://www.hesa.ac.uk/news/20-07-2017/graduates-employment.

Jones, P.J., Forbes-Simpson, K., Maas, G. and Newbery, R. (2015). Beta: An experiment in funded graduate start-up, Industry and Higher Education, 29 (5), pp. 405-418.

Kolb, D. (1984). Experiential learning as the science of learning and development, Englewood Cliffs, NJ: Prentice Hall.

Matlay, H. (2008). The impact of entrepreneurship education on entrepreneurial outcomes, Journal of small business and enterprise development, 15(2), pp.382-396.

Nabi, G., Liñán, F., Fayolle, A., Krueger, N. and Walmsley, A. (2017). The impact of entrepreneurship education in higher education: A systematic review and research agenda, Academy of Management Learning \& Education, 16(2), pp.277-299.

Oosterbeek, H., Van Praag, M. and Ijsselstein, A. (2010). The impact of entrepreneurship education on entrepreneurship skills and motivation, European economic review, 54(3), pp.442-454.

Phillips, R. A. (2018). A Retrospective Study on the Views of Alumni Entrepreneurs Towards University Enterprise Education and Training, IUP Journal of Knowledge Management, 16(3). pp.54-71.

Phillips, R. A. (2017). Measuring Entrepreneurial outcomes from a Residential Enterprise School for Postgraduate Researchers, Journal of Asia Entrepreneurship and Sustainability, 13(2), pp.62-89.

Phillips, R. A. (2010). Encouraging a more enterprising researcher: the implementation of an integrated training programme of enterprise for $\mathrm{Ph}$. D. and postdoctoral researchers, Research in Post-Compulsory Education, 15(3), pp.289-299.

Phillips, R.A. (2008). The Use of Personal Journals for Assessment of an Undergraduate Enterprise Module, Journal of Asia Entrepreneurship and Sustainability 4 (4), pp.7789.

Phillips, R.A. and Styles, J. (2006). Case studies and lessons learned from a Masters of Enterprise, Proceedings of the $16^{\text {th }}$ IntEnt Conference (2006), Sao Paulo, Brazil.

QAA, Quality Assurance Agency for Higher Education (2018). Enterprise and entrepreneurship education guidance for UK higher education providers, available online at: http://www.qaa.ac.uk/en/Publications/Documents/Enterprise-andentrpreneurship-education-2018.pdf. 
Sanchez-Romaguera, V. and Phillips, R.A. (2018). A comparison of a first and final year UG enterprise unit: lessons from experiential learning and interdisciplinarity, Proceedings of the 4th International Conference on Higher Education Advances (HEA'd 2018), pp.899-907.

Smith, A.J., Collins, L.A. and Hannon, P.D. (2006). Embedding new entrepreneurship programmes in UK higher education institutions: Challenges and considerations, Education and Training, 48, pp.555-567.

Souitaris, V., Zerbinati, S. and Al-Laham, A. (2007). Do entrepreneurship programmes raise entrepreneurial intention of science and engineering students? The effect of learning, inspiration and resources, Journal of Business venturing, 22 (4), pp.566-591.

Vesper, K. H., and Gartner, W. B. (1997). Measuring progress in entrepreneurship education, Journal of Business venturing, 12(5), pp.403-421.

Volkman, C., Wilson, K.E., Rabuzzi, D., Vyakarnam, S., Sepulveda , A. (2009). Educating the next wave of entrepreneurs: Unlocking entrepreneurial capabilities to meet the global challenges of the 21st century. A report of the Global Education Initiative, available on-line at: http://www.weforum.org/pdf/GEI/2009/Entrepreneurship_Education_Report.pdf. 